suppression test without any of its hazards or wasting the patient's time. At present apparently a normal response of TSH to a small intravenous dose of thyrotrophin-releasing hormone virtually excludes appreciable hyperthyroidism, while an absent response usually but not necessarily indicates hyperthyroidism, especially in an untreated patient.

The TSH immunoassay has now proved itself to be a valuable test of thyroid function, particularly in the diagnosis of mild hypothyroidism. TSH measurements after the administration of thyrotrophin-releasing hormone also provide helpful information in the diagnosis of hypothyroidism secondary to pituitary-hypothalamic disease and in recognizing minor degrees of thyroid overactivity.

1 Utiger, R. D., Annals of Internal Medicine, 1971, 74, 627.
2 Hedley, A. J., Hall, R., Amos, J., Michie, W., and Crooks, J., Lancet, 1971, 1, 455 .

3 Slingerland, D. W., Dell, E. S., and Burrows, B. A., in Abstracts of the Sixth International Thyroid Conference, Vienna, June 1970.

- Ormston, B. J., Garry, R., Cryer, R. J., Besser, G. M., and Hall, R., Lancet, 1971, 2, 10.

Bastenie, P. A., Vanhaelst, L., and Neve, P., Lancet, 1967, 2, 1221.

Bastenie, P. A., Vanhaelst, L., Bonnyns, M., Neve, P., and Staquet, M., Lancet, 1971, 1, 203.

7 Fowler, P. B. S., and Swale, J., Lancet, 1967, 1, 1077.

8 Fowler, P. B. S., Swale, J., and Andrews, H., Lancet, 1970, 2, 488.

Hall, R., Amos, J., and Ormston, B. J., British Medical fournal, 1971, 1,

582.
10 Hershman, J. M., and Pittman, J. A., Annals of Internal Medicine, 1971,

11 Hall, R., Amos, J., Garry, R., and Buxton, R. L., British Medical fournal, 1970, 2, 274.

12 Ormston, B. J., and Hall, R., in A Workshop Conference on ThyrotrophinReleasing Hormone, ed. R. Hall, I. Werner, and H. Holgate. Basel, Releasing Hormone, ed. $\mathrm{R}$.
$\mathrm{S}$. Karger, 1971, in press.

13 Lawton, N. F., Ekins, R. P., and Nabarro, J. D. N., Lancet, 1971, 2, 14.

\section{Animal Experiments}

The increase each year in the number of laboratory animals used for research and for various purposes in the pharmaceutical and related industries is reflected in the annual Home Office returns of experiments. ${ }^{1}$ These cover Great Britain, but the increase is paralleled in other countries throughout the world and is in itself proof that animal experimentation produces useful results. No scientist or businessman would put himself to the trouble and expense of using animals for investigations if an in vitro test would serve as well. Yet paradoxically the very usefulness of animal experiments begs the question whether, having found a system that gives such consistently valuable results, scientists are giving enough consideration to alternative methods.

The Consultative Assembly of the Council of Europe adopted a recommendation ${ }^{2}$ in January 1971 that was severely critical of accepted uses of experimental animals. The recommendation is supported by a summary of evidence collected by several rapporteurs. ${ }^{3}$ The council's general thesis is that animal experimentation is used too readily and that a commission should be set up to study alternative methods by various means-some of which would duplicate existing activities-with the hope that ultimately animal experiments might be altogether abandoned. A serious bias may be detected in the evidence collected by the rapporteurs. More than twice as much space is given to evidence from those supporting the council's thesis, many of them frank antivivisectionists, than to evidence from scientists who see no reason for any radical change. In fact, the very incompleteness of the evidence is open to grave criticism, and it is little wonder that the World Medical Association in September rejected the Council of Europe's recommendation. ${ }^{4}$
Nevertheless, this will not be the end of the controversy, nor should it be. Animal experimentation has produced and will continue to produce results of benefit to human and animal medicine and life in general. A minority of experiments cause suffering, and fewer still severe suffering. Suffering should be prevented on ethical grounds and because it is almost certain to vitiate the experiment. The aim should therefore be not to abandon a method of investigation that is so valuable but to remove from it the undesirable features of pain and suffering.

The subject of animal experimentation is never far from the public or the medical mind. The Universities Federation for Animal Welfare held a symposium in October on the rational use of animals in research, and in May two other symposia on different aspects of the same theme were held by the Laboratory Animal Science Association and jointly by the Comparative Medicine Section of the Royal Society of Medicine and the Research Defence Society. The Littlewood Committee Report ${ }^{5}$ is still under consideration by the Home Office, which has already given effect to some of its recommendations. If for many good reasons the Council of Europe's recommendation is unacceptable there is nevertheless a need for those who are better equipped to weigh the matter than some whose evidence was presented by the Council of Europe to work out a more rational, better informed approach to the ethical problems of animal experiments. These should concern a civilized society, and it would be wrong to sweep the whole thing under the carpet.

1 Home Office, Annual Return of Experiments Performed under the Cruelty of Animals Act, 1876. London, H.M.S.O.

2 Consultative Assembly of the Council of Europe, Twenty-second Ordinary Session, 3rd part, 20 January 1971, Recommendation 621. London, H.M.S.O., 1971

Consultative Assembly of the Council of Europe, Twenty-second Ordinary Session, 3rd part, 20 January 1971, Recommendation 621. Documents 2874 and 2875. London, H.M.S.O., 1971.

British Medical fournal Supplement, 1971, 4, 3.

Departmental Committee on Experimental Animals, Report, Cmnd. 2641. London, H.M.S.O., 1965.

\section{Ovarian Tumours in Infants and Children}

Gynaecologists and surgeons are seldom called on to treat ovarian tumours in children, common though these lesions are in later life. I. Forshall ${ }^{1}$ reported only 21 cases of ovarian tumour in over 100,000 patients admitted to two Liverpool children's hospitals, and D. S. Thatcher ${ }^{2} 48$ cases in nearly 160,000 admissions to the Milwaukee Children's Hospital. Moreover, the clinical and pathological features of ovarian tumours in childhood differ in some ways from those in adults. Diagnosis is more difficult and mistakes are therefore more often made. Torsion of the tumour is more often the presenting feature and abdominal pain a more common symptom, and thus appendicitis rather than torsion of a tumour is apt to be diagnosed. The epithelial tumours so frequently found in adults are less common in children, but teratomatous lesions, benign or malignant, and dysgerminomata are relatively more common.

The different histological pattern of childhood ovarian new growths is shown by $\mathrm{O}$. Lindfors ${ }^{3}$ in a report on 81 cases of primary ovarian neoplasm in Finnish and Swedish children of up to 14 years of age. Only 10 tumours were 
in the cystadenomatous group compared with 20 in the group of embryonal carcinoma or malignant teratoma, 17 innocent dermoid cysts, 15 dysgerminomata, and 8 granulosa-cell tumours. Abdominal pain was the commonest symptom and also the commonest first symptom in Lindfors's patients. Three-quarters of the children had a palpable abdominal swelling, though the mass was not always recognized when the patient was first seen-an indication of the more difficult diagnostic problems in this age group. Indeed, in the group as a whole there was an average delay of three to four months from the time of first examination to the time of diagnosis. When no tumour is palpable Lindfors stresses the value of a plain abdominal $x$-ray examination, which may show teratomatous calcification and may rule out other disorders. Nevertheless, a preoperative diagnosis was not always possible and operation was performed in $21 \%$ of cases on a provisional diagnosis of appendicitis.

A surgeon may find it difficult to decide how extensive his operative treatment should be, especially when he comes on the ovarian tumour unexpectedly. The treatment in 27 cases of innocent neoplasm in Lindfors's series was salpingooophorectomy in 17 and cystectomy in only 10. A simple cystic ovarian tumour is probably (though not certainly) innocent, while dermoid cysts are readily recognizable if shelled out from the ovary and inoised, when their typical contents are seen. Conservation of ovarian tissue is most important in children, and initially cystectomy is generally preferable to either oophorectomy or salpingo-oophorectomy for probably innocent lesions. But lesions that are possibly malignant call for removal of all the affected ovary. When this seems completely to have removed the macroscopic tumour no more need be done, apart from careful follow-up. A more extensive malignant lesion, with spread to the opposite ovary, the uterus, or elsewhere, can seldom be dealt with satisfactorily by other than total hysterectomy and bilateral salpingo-oophorectomy, and not always then. In Lindfors's series $52 \%$ of the children with malignant lesions survived alive and well for two years. After that there were no fatalities in $74 \%$ of the survivors who were followed up for five years, and none in $30 \%$ who were followed up for 10 years.

Awareness that little girls may develop ovarian neoplasms together with greater insistence on careful abdominal and rectal examination in any child with abdominal pain will lead to earlier and more reliable diagnoses, which are so important to ultimate survival.

\footnotetext{
1 Forshall, I., Archives of Diseases in Childhood, 1960, 35, 17.

2 Thatcher, D. S., Surgery, Gynecology and Obstetrics, 1963, 117, 477.

${ }^{3}$ Lindfors, O., Annales Chirurgiae et Gynaecologiae Fenniae, 1971, 60, Supplement 177.
}

\section{Screening for Mental Disorder}

Psychiatric screening was being tried fifty years ago. "Every effort should be made at the time of enlistment to ascertain the nervous and mental conditions of candidates both from their previous histories and from their present condition. Only fit men ... should be enlisted into the regular Army." In the second world war, too, efforts were made to exclude unsuitable people from war service and from air crews ${ }^{2}$ as well as to choose people for training as officers.

This type of screening is designed, as is quarantine, to protect society from the individual. In a newer sense screening means the discovery of presymptomatic disease or of disease in its early stages, and it is employed primarily for the benefit of the individual. But initial enthusiasm, largely generated by the success of mass miniature radiography in detecting early cases of pulmonary tuberculosis, has waned. It has been succeeded by a more cautious phase marked by the publication in 1968 of two authoritative reports. ${ }^{34}$ The first enunciated ten principles as guides to planning casefinding. The second subjected ten widely used screening procedures to rigorous analysis and found that all of them could be criticized on the grounds that too little is known of the natural history of the diseases concerned, or that the best available methods of diagnosis and treatment are unsatisfactory, or that the poor haul hardly justifies the cost of trawling.

Since then controversy has erupted over, for example, screening for phenylketonuria, in which for ethical reasons a controlled trial of dietary treatment has not been carried out. Ironically, too, the arrangements for random detection of tuberculosis by mass radiography are being phased out. ${ }^{5}$ Nevertheless programmes of screening for a single disease or a multiplicity of them go ahead, particularly in the United States and in a few places in Britain. Screening for hypertension, at least in middle-aged men, has also staged a comeback. ${ }^{6}$

Any proposal to introduce an entirely new screening programme is likely to be resisted and before being accepted will have to be judged by the ten principles of J. M. G. Wilson and G. Jungner ${ }^{3}$ (or something like them). According to these the disorder to be screened should be important and it should have a recognizable latent or presymptomatic stage; the disease should be treatable and facilities for diagnosis and treatment should be available; tests for the disorder should be reliable and acceptable; the natural history of the condition should be understood; there should be a cut-off point between those found to need and those found not to need treatment; and the cost-effectiveness of screening should compare with that of other medical services.

Recently M. R. Eastwood ${ }^{7}$ assessed psychiatric disorder as a candidate for screening. He found it at present unsuitable in almost every respect and concluded: "The problems of definition of diagnostic categories, knowledge of the natural history of neurosis, and effectiveness of treatment require solving." In addition, there are disagreements about diagnosis-notably between British and American psychiatrists - of the psychoses, 89 admittedly only a small proportion of the whole. The disparities exist too between textbook descriptions of neurosis, which are apt to give the hospital view, and the facts of minor nervous illness as general practitioners see them. Who can say when exactly the worrier stumbles over the line into an anxiety state or when moodiness deserves the name depression? Exactly where is the presymptomatic stage in these disorders? General practitioners already provide diagnostic facilities and treatment for $90 \%$ of patients presenting with psychiatric symptoms. ${ }^{10}$ If screening were to provide more patients, could they be treated?

Eastwood reviews the known facts about the distribution of psychiatric disorder and shows how with community surveys and general practice surveys we have come some way towards establishing prevalence rates in the population at large. These rates may be similar in places as far apart 